\title{
11 - A Ocorrência das Células Anexas dos Estômatos na Família Rubiaceae (*)
}

\author{
Walter Radamés Accorsi \\ Prof. de Botânica da \\ Escola Superior de Agricultura \\ "Luiz de Queiroz", Universidade \\ de São Paulo
}

1 - Introdução

fNDICE

2 - Material e Método

157

159

5 - Abstract

162

2 - Discussão

6 - Bibliografia consultada 102

159

7 - Agradecimentos

163

4 - Resumo e Conclusões

161

8 - Explicação das figuras 168

\section{I - INTRODUÇAO}

Baseado na descrição feita por AVERNA SACA (1) das células anexas que acompanham os estómatos de Coffea arabica L., as quais, segundo HABERLANDT (6) fazem, tambem, parte integrante do aparelho estomatar, resolvi investigar a ocorrência daquelas células entre as Rublaceae. A principlo, examinel cuidadosamente o material obtido de 9 generos de Rubiaceae; num total de 20 espécies, todas cultivadas om tarre-

(*) Recebido para publicação em 13 de Janeiro de 1945. 
nos dia Escola Superior de Agricultura "Luiz de Queiroz", verificando em todos os exemplares, a presença das células anexas, adjacentes às células estomáticas, a par da semelhança morfológica revelada pelos estômatos. Deante dêsses fatos, aventei a possibilidade de tal organização estomatar ser peculiar às espécies e gêneros das Rubiaceae e que, uma vez confirmada, passaria a constituir um caráter anatômico de famiiia, dependendo, naturalmente, da freqüência de sua distribuicão nos grupos sistemáticos consideradcs. Para tanto, duas hivotest:s deviam ser satisfeitas:

1 - Que a família Rubiaceae fosse a única. dentre as que constituem a ordem Rubiales e familias afins, a apresentar as duas células anexas na estrutura dos estômatos e com as características morfológicas já assinaladas.

2 - Que a referida organização estomatar fosse peculiar às espécics ou aos gêneros das Rubiaceae, podendo constituir, mesmo no caso de sua inconstância, um caráter diferencial.

De acôrdo com o meu trabalho, que publiquei na revista "O Solo" (2), a primeira hipótese ficou demonstrada, isto é, a Sumilia Rubiaceae é a única da: ordern Rubiales a exibir estômatos círcundados de duas células anexas. Das familias consideradas afins das Rubiaceae (5), apenas a espécie Tabebuia rassinoides Pyr. D. C., entre as Bignoniaceae por mim examinadas, revelou estrutura estomatar semelhante à encontrada nas espécies de Rubiaceae. Entretanto, a familia Bignoniaceae pertence à ordem Tubiflorae e, consoante as pesquizas sérumdiagnósticas (7), mostra um escasso parentesco com a Rubiales. Por essa razão, a ocorrência das células anexas nos estómatos de Tabebuia cassinoides Pyr. D. C., não possui grande importáncia em relação ao caso vertente; contudo, deixaria, ipenas, entrever a possibilidade de um parentesco afastado com as Rubiaceae, porque LöFGREN (5), ao assinalar as afiriidades das Rubiaceae com as familias correlatas, escreve: "As Loganiáceas vêm em seguida, mas já se afastam pela sua anatomia geral, luastante diferente. Resta, ainda, para estudar o gênero Henriquezia para verificar se não são mais pronunciadas as afinidades com as Bignoniaceae, do que têm sido admitido até hoje".

Quanto à segunda hipótese, ficou estabelecido que se estudassem, em primeiro lugar, as principais espécies e varie- 
ciades do gênero Coffea, e, depois, o maior número de gêneros da familia, a-fim-de se chegar a uma conclusão sôbre o valor das células anexas dos estômatos como caráter anatômico das Rubiaceae.

\section{3 - MATERIAL E MÉTODO}

Em prosseguimento aos estudos iniciados e de conformiaade com o plano traçado, apresento, neste trabalho, os resultados das observaçōes feitas sôbre os estômatos de 24 variedadés de Coffea arabica $L$. e de mais 4 espécies de Coffea, num lotal ôf 28 indivíduos. Deixam de figurar determinadas espéries e variedades de Coffea, por não ter podido obter, no momento, material para estudo.

O material de Coffea investigado, compreendendo fôlhas adultas e sãs de plantas normais, foi obtído da Coleção de Cafeeiros da Secção de Café (*) do Instituto Agronômico, em Campinas.

Para a extração e montagem da epiderme, empreguei a técnica usada nas minhas primeiras investigações para o estudo da organização dos estômatos em Rubiaceae. Utilizei-me, ainda, do microscópio Universal "Me $F$ " Reichert e do mesmo jôgo ótico usado da 1.a vez, isto é, objetiva Reichert $100 \mathrm{x} \mathrm{n}$. p. a ocular $5 \mathrm{x}$, para a projeção de trechos epidérmicos e confecção cos desenhos, inclusivé a escala micrométrica, destinada às mensurações.

\section{3 - DISCUSSÃO}

As espécies, variedades e formas estudadas são as constantes da relação abaixo. Embora algumas das variedades tenham sido já analisadas no meu primeiro trabalho (2), achei conveniente citá-las, outra vez, para uma melhor apreciação e comparação dos estômatos, do ponto de vista das células anexas nas demais variedades e espécies de Coffea.

1 - Coffea excelsa Chevalier

2 - Coffea congensis Froehner

3 - Coffea canephora (Robusta) Pierre ex Froehner

4 - Coffea liberica Bull. ex Hiern

5 - Coffea arabica L. var. typica Cramer

$\therefore$ Ao chefe da Secçāo de Café, Dr. J. E. T. Mendes e dignissimos assistentes, ns agradecimentos do Autor. 
- Coffea arabica L. var. typica Cramer, forma xantocarpa (Caminhoá) Krug

7 - Coffea arabica L. var. bourbon (B. Rodr.) Choussy

8 - Coffea arabica L. var. bourbon (B. Rodr.), ' forma xanthocarpa f. nov.

9 - Coffea arabica L. var. maragogipe Hort. ex Froehner

10 - Coffea arabica L. var. maragogipe Hort. ex Froehner, forma xanthocarpa

11 - Coffea arabica L. var. angustifolia (Roxb.) Miq.

12 - Coffea arabica $L$. var. bullata Cramer

13 - Coffea arabica L. var. erecta Ottoländer

14 - Coffea arabica $L$. var. goiaba Taschdjian.

15 - Coffea arabica L. var. laurina (Smeathman) D. C.

16 - Coffea arabica L. var. mokka Hort. ex Cramer

17 - Coffea arabica L. var. murta Hort. ex Cramer

18 - Coffea arabica L. var. pendula Cramer

19 - Coffea arabica L. var. polysperma Burck

20 - Coffea arabica L. var. purpurascens Cramer

21 - Coffea arabica L. var. anomala nov. var.

22 - Coffea arabica $L$. var. calycanthema nov. var.

23 - Coffea arabica $L$. var. cera nov. var.

24 - Coffea arabica $L$. var. semperflorens nov. var.

25 - Coffea arabica L. var. monosperma Ottoländer et Cramer

26 - Coffea arabica $L$. var. variegata Cramer

27 - Coffea arabica L. var. nana

28 - Coffea arabica $L$. var. tetramera nov. var.

O exame geral da constituição dos estômatos pelas suas paredes periclinas, dos individuos estudados, faz ressaltar, de pronto, a extraordinária semelhança que existe entre êles quanto à forma, dimensões e disposição das duas células anexas. Estas, em cada estômato, são de tamanhos diferentes e de formas, em geral, distintas; dispõem-se lado a lado das células estomáticas, à guisa de alças, conforme se pode verificar do exame dos desenhos que ilustram êste trabalho. $O$ contôrno das células anexas, nas espécies, variedades e formas estudadas, é variável, podendo ser uma linha ligeiramente poligonal, sinuosa ou crenada e até uma semicircunferência. As extremidades de cada contôrno se unem às do outro e, do ponto de junção, se origina um segmento de mebrana bem curto, que se prolonga até se inserir nas paredes das células estomáticas, em lugares variáveis. Comumente, a inserção se dá nas extremidades da fenda estomática (ver desenhos). eviden- 
te que no mesmo trecho epidérmico se encontram pequenas variacões na estrutura dos estómatos, no que diz respeito ao tamanho, ligação e inserção das células anexas com as estomáticas (ver desenhos), porém, a configuração geral permanece pràticamente uniforme, mormente entre as variedades e foryas la mesma espécie. Essa homogeneidade de forma nos estômatos dos individuos da mesma espécie e variedade, aliad́a à fréquiência, será de grande importância para a identificação e separação dos gêneros, possivelmente, das de mais espécies e variedades de Rubiaceae, caso fique demonstrada a segunda hipótese formulada. Acredito que a estrutura aprèsentada pelas espécies e variedades estudadas seja geral no gênero Coffea, embora não tenha podido examinar material mais abundante, por näo existir, atualmente, entre nós. Autoriza-me a suposicão supra a presença de estruturas semelhantes em gêneros bem afastados de Coffea, segundo ficou provado no meu primeiro trabalho (2). Nessas condições, os 28 exemplares estudados seriam considerados suficientes para se generalizar a ocorréncia das células anexas dos estómatos em Coffea. Contudo, para o futuro, quando houver facilidade de se conseguir material das demais espécies de Coffea, farei uma apreciação mais completa nesse sentido.

Ocorrem, ainda, de permeio com os estômatos isolados, estômatos geminados, isto é, que manteem entre si contacto através das células anexas. A ligação mais frequiente é pelas células j.nexas maiores; a extensão do contacto é variável e depende da posição dos estômatos, os quais oferecem, neste particular, uma grande diversificação de aspectos. (Figs. 6, 8, 10, 11, 12, 13, $15,17,18,19,21$ e 23). Mais raramente se encontra o caso de inversão das posições com pareamento lateral, isto é, união das células anexas grandes e pequenas (Figs. 14 e 20), ou, ainda, o caso da célula anexa maior de um se urir a duas do outro iFig. 16).

Fica, pois, ampliada, com as observações realizadas até agora entre espécies, variedades e formas de Coffea, a ocorrência das células anexas dos estômatos na familia Rubiaceae. Res1:a-me, pois, estudar o maior número de gêneros de tăo importante familia para poder, então, chegar a uma conclusão dejinitiva sôbre o valor sistemático dos estômatos, tais como sāo cirganizados, para as Rubiaceae.

\section{4 - RESUMO E CONCLUSÕES}

No trabalho que publiquei sôbre a estrutura dos estômatos 
$€ \mathrm{~m}$ relação às células anexas, na revista "O Solo" (2), ficou comprovado que na ordem Rubiales a familia Rubiaceae é a única a apresentar a referida estrutura, o que me levou a sugerir a possibilidade de considerá-la como um caráter anatômico dos gêneros ou das espécies da família, dependendo da sua freqüência nos mencionados grupos. Em vista disso, resolvi estudar o maior número de gêneros e espécies de Rubiaceae, em relação à estrutura estomatar, começando pelo gênero Coffea, dada a sua grande importância econômica. Analisei 28 individuos, atraz relacionados e verifiquei, em todos, a constância das células anexas, de configuração bastante homogênea, detalhe êste que poderá servir de base a distinções entre os grupos sistemáticos estudados. No próximo artigo tratarei de outros gêneros de Rubiaceae.

\section{5 - ABSTRACT}

This paper deals with stomata strucutre in the Rubiaceae family. This family in the order Rubiales is the only one to show the stomata structure relationed to the subsidiary cells. Twentyeight individuals representing several forms, varieties and especies of the genus Coffea were studied and the uniformity regarding that structure observed.

It is possible that the stomata structure, studied in detail in this paper, is a good character to distinguish the Rubiaceae family. Analysis of the other genus wil be carried on in order io confirm the observations made in the genus Coffea.

\section{6 - BIBLIOGRAFIA CONSULTADA}

1 - AVERnA SACA, R - 1913 - Postila de Botânica Geral e Sistemática.

2 - ACCORSI, W. R. - 1941 -- Revista "O Solo", ano XXXIII, número único. Tip. Aloisi - Piracicaba - pags. 27 a 37.

3 - BERNEGG, SPRECHER von - 1939 - Plantas Tropicais e Sub-Tropicais da Economia Mundial - O CAFÉ, Edição do Departamento Nacional do Café - emprêsa Gráfica "O Cruzeiro" - Rio.

4. - Krug, C. A., MENDES, J. E. T.e CARVALHO, A - $1939-$ Taxonomia de Coffea arabica $L$ - Boletim Tecnico n. 62 - Instituto Agronomico do Estado, em Campinas, Sec. da Agricultura. - Comp. Melhoramentos de S. Paulo.

5 - LöfGREN, A - 1917 - Manual das Familias Phamerogamas, Imprensa Nacional, Rio de Janeiro. Pag. 514. 
6 - HABERLANDT, G. - 1928 - Physiological Plant Anatomy, Macmillan Cia., London. Pag. 446.

i - WETTSTEIN, R. 1927 - Botânica Sistemática - Unione Tipográfico - Editrice Torinese, Torino. II Vol. pag. 394.

\section{7 - AGRADECIMENTOS}

O Autor agradece ao Snr. Alvaro P .Sega a confecçáo dos ciesenhos constantes dêste trabalho.

\section{8 - EXPLICAÇAO DAS FIGURAS}

Em tôdas a figuras, A e $B$ representam as células anexas. $A s$ variedades de números 25 a 28 relacionadas no texto não foram desenhadas, por achar que as ilustrações apresentadas são suficientes para os fins visados neste trabalho.

1 - Coffea excelsa Chevalier

? - Coffea congensis Froehner

3 - Coffea canephora (Robusta) Pierre ex Froehner

4 - Coffea liberica Bull. ex Hiern

5 - Coffea arabica L. var. typica Cramer

6 - Coffea arabica L. var. typica Cramer, forma xanthocarpa (Caminhoá) Krug

7 - Coffea arabica L. var. bourbon (B. Rodr.) Choussy

3 - Coffea arabica L. var. bourbon (B. Rodr.), forma xanthocarpa f. nova

9 - Coffea arabica L. var. maragogipe Hort. ex Froehner

10 - Coffea arabica L. var. maragogipe Hort. ex Froehner, forma xanthocarpa

11 - Coffea arabica L. var. angustifolia (Roxb.) Miq.

12 - Coffea arabica L. var. bulata Cramer

13 - Coffea arabica L. var. erecta Ottoländer

14 - Coffea arabica L. var. goiaba Taschdjian

15 - Coffea arabica L. var. laurina (Smeathan) D. C.

16 - Coffea arabica L. var. mokka Hort. ex Cramer

17 - Coffea arabica L. var. murta Hort. ex Cramer

18 - Coffea arabica L. var. pendula Cramer

19 - Coffea arabica L. var. polysperma Burck

20 - Coffea arabica L. var. purpurascens Cramer

21 - Coffea arabica L. var. anomala nov. var.

22 - Coffea arabica L. var. calycanthema nov. var.

23 - Coffea arabica L. var. cera nov. var.

24 - Coffea arabica L. var. semperflorens nov. var.

Nota : - todos os desenhos são originais. 

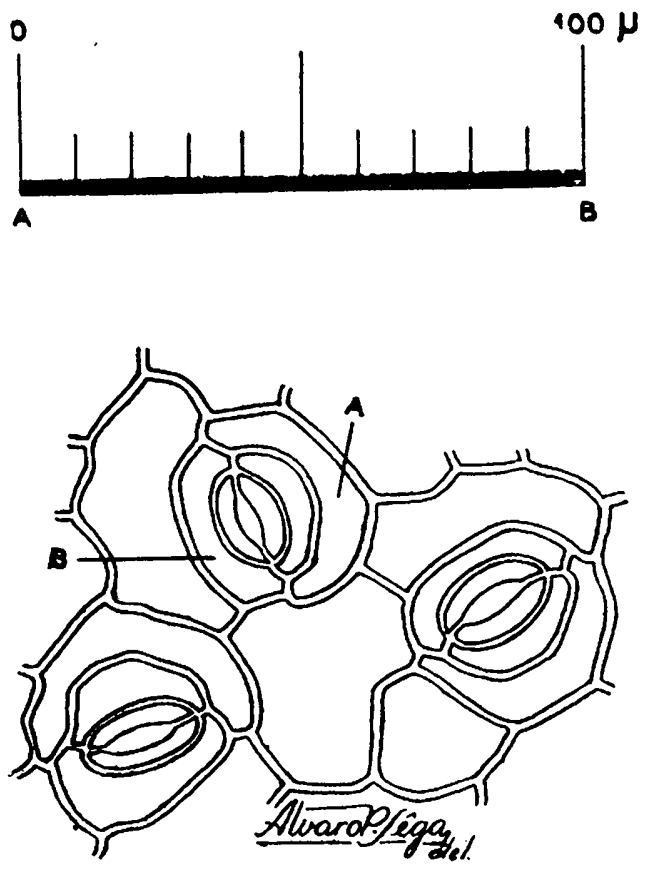

Fig. 1

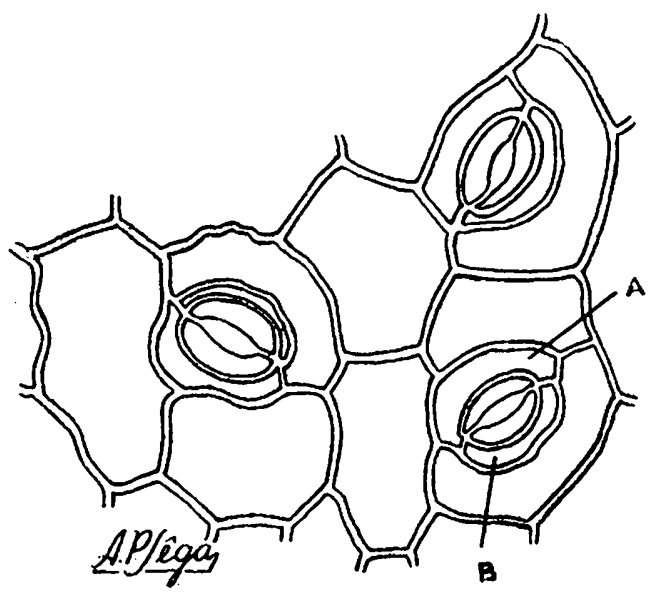

Fig. 2 


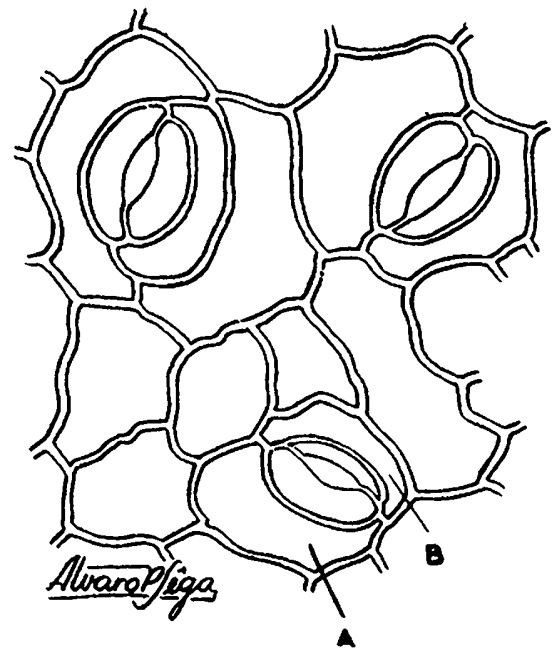

Fig. 3

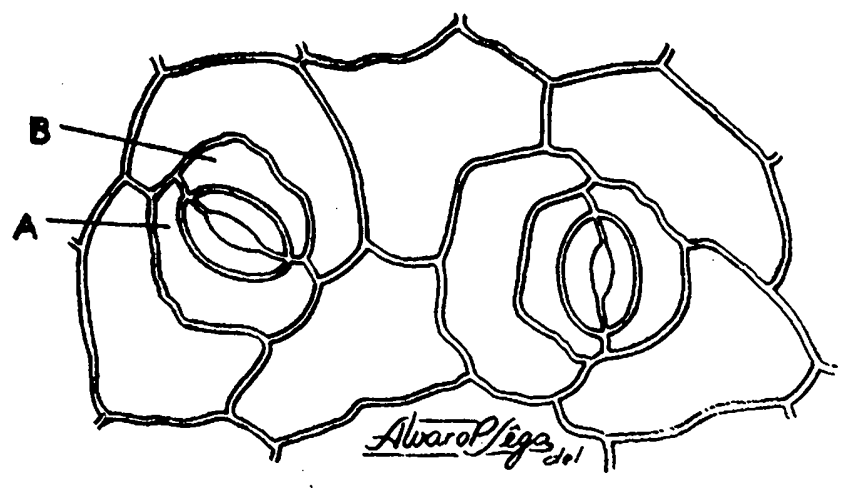

Fig. 4 


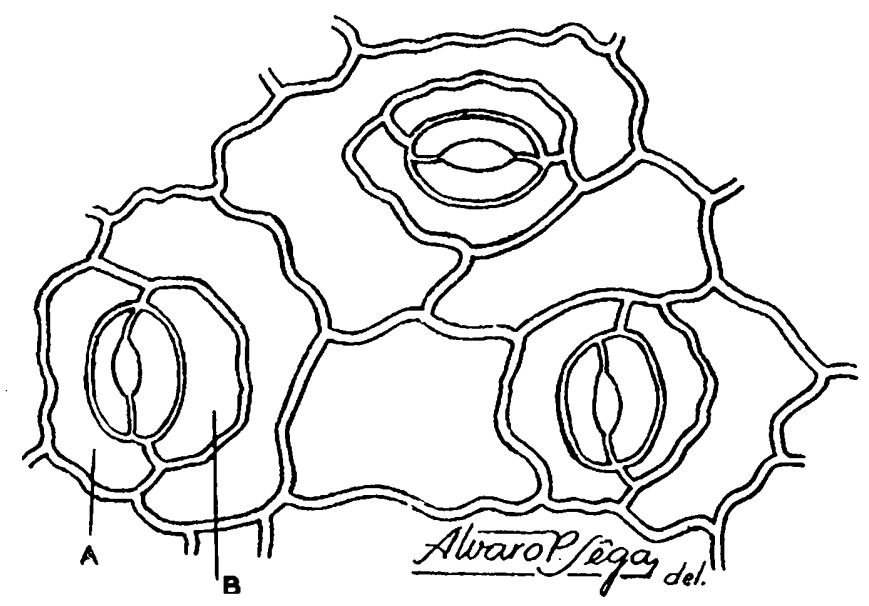

Fig. 5

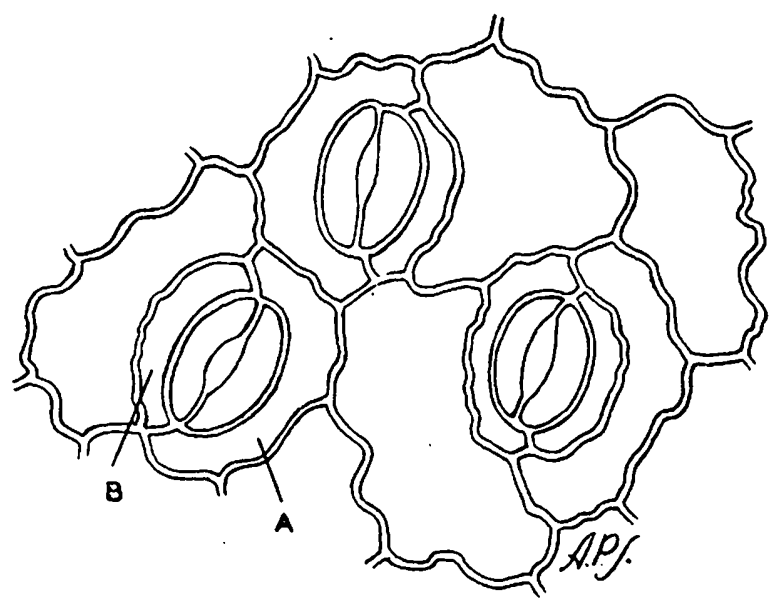

Fig. 6 

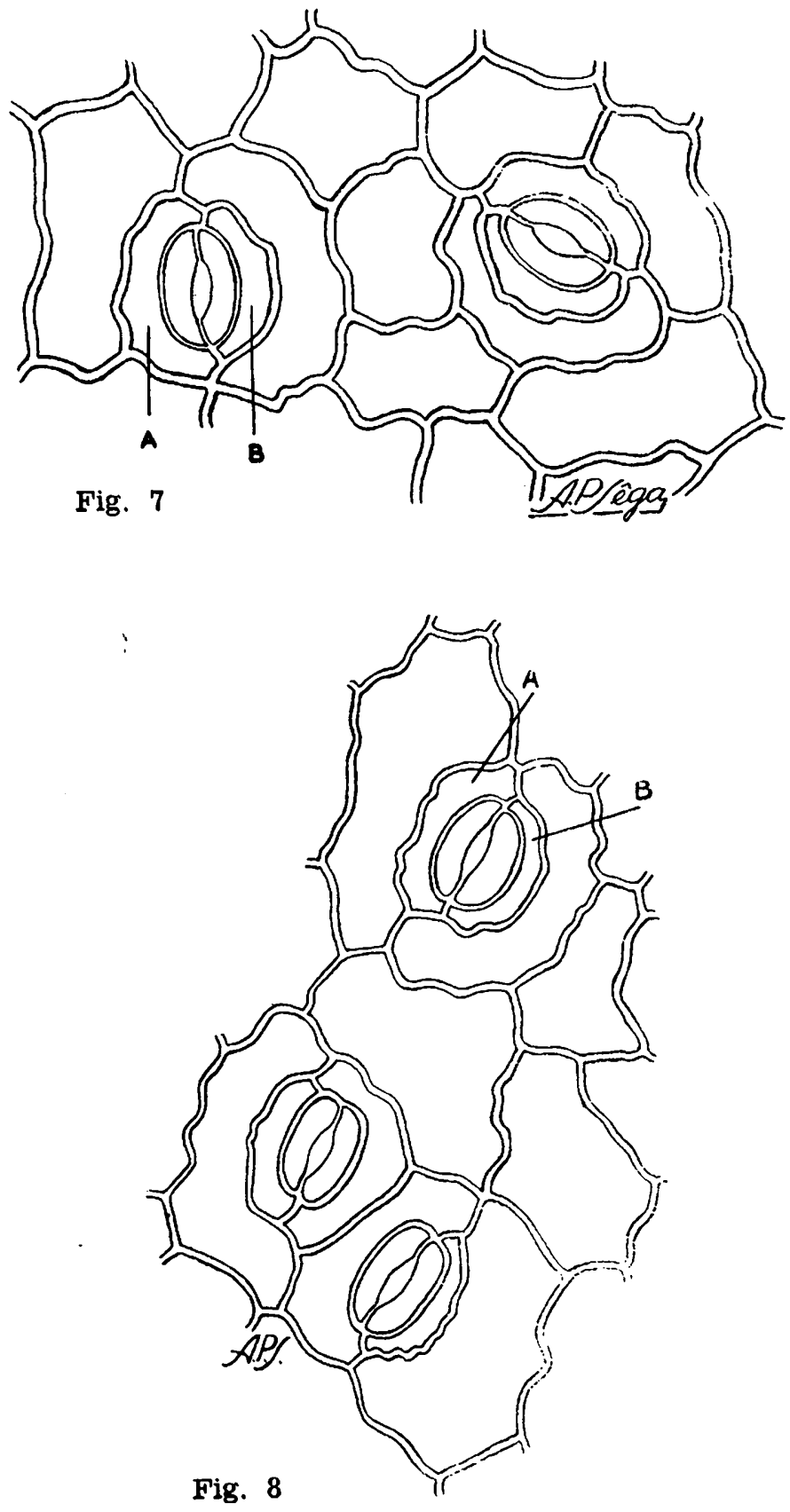


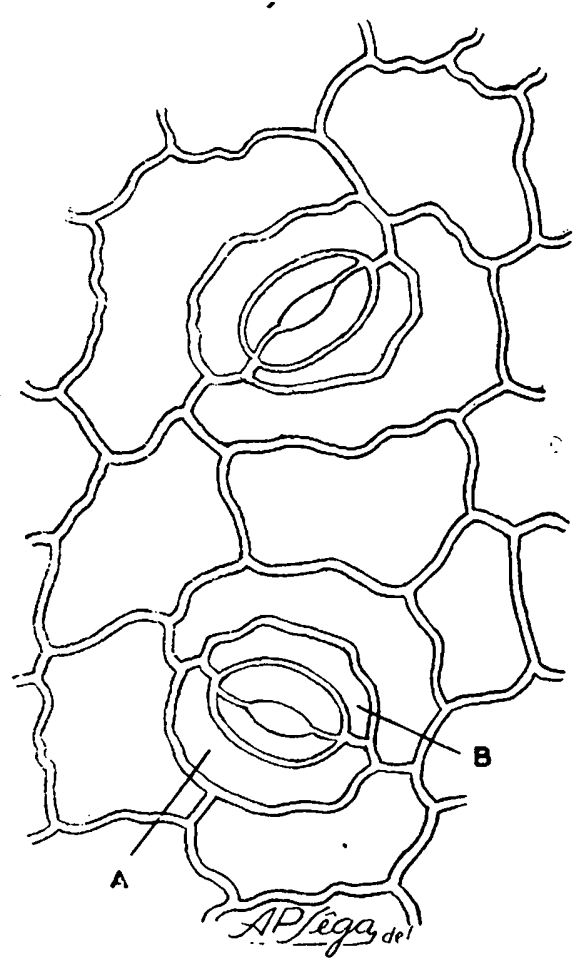

Fig. 9

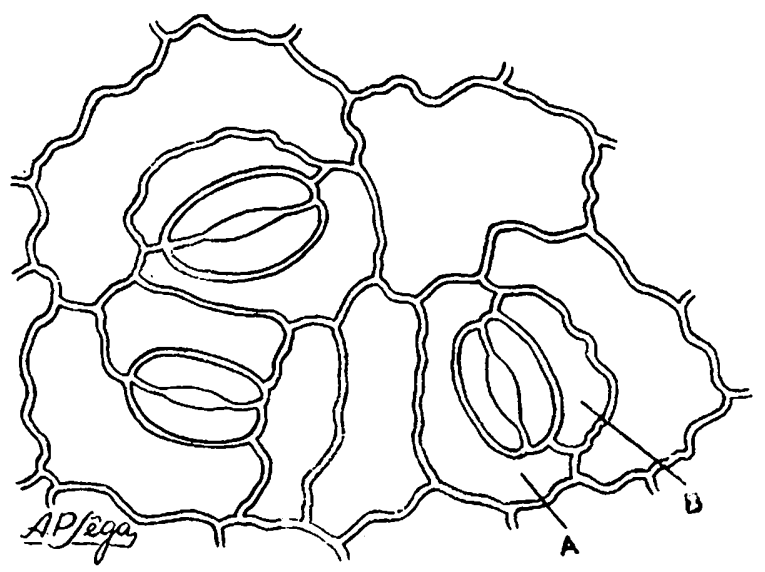

Fig. 10 


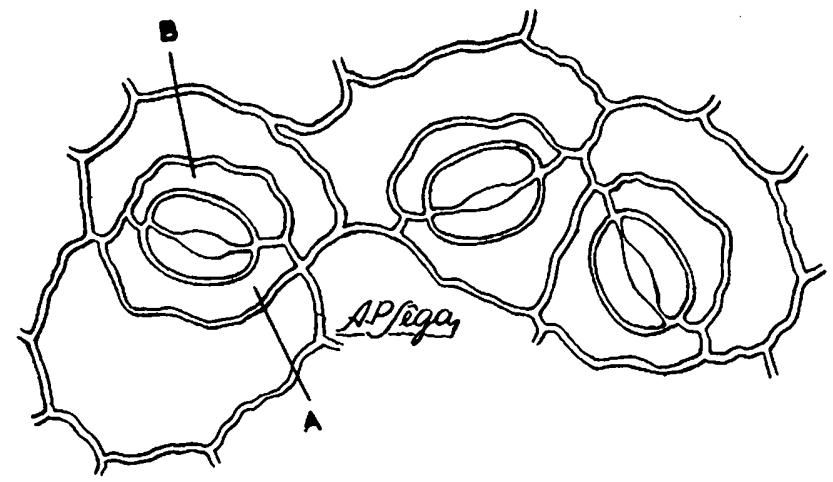

Fig. 11

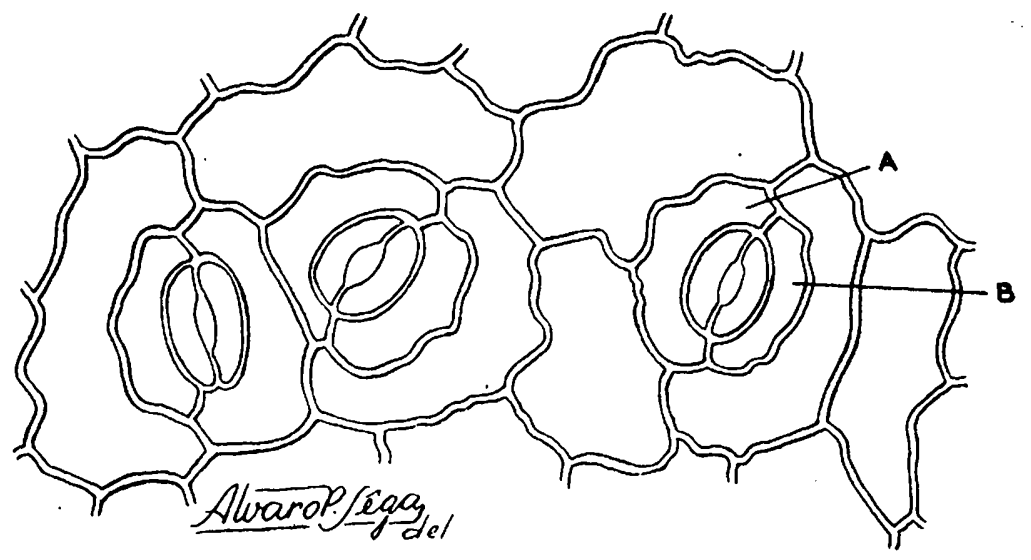

Fig. 12 

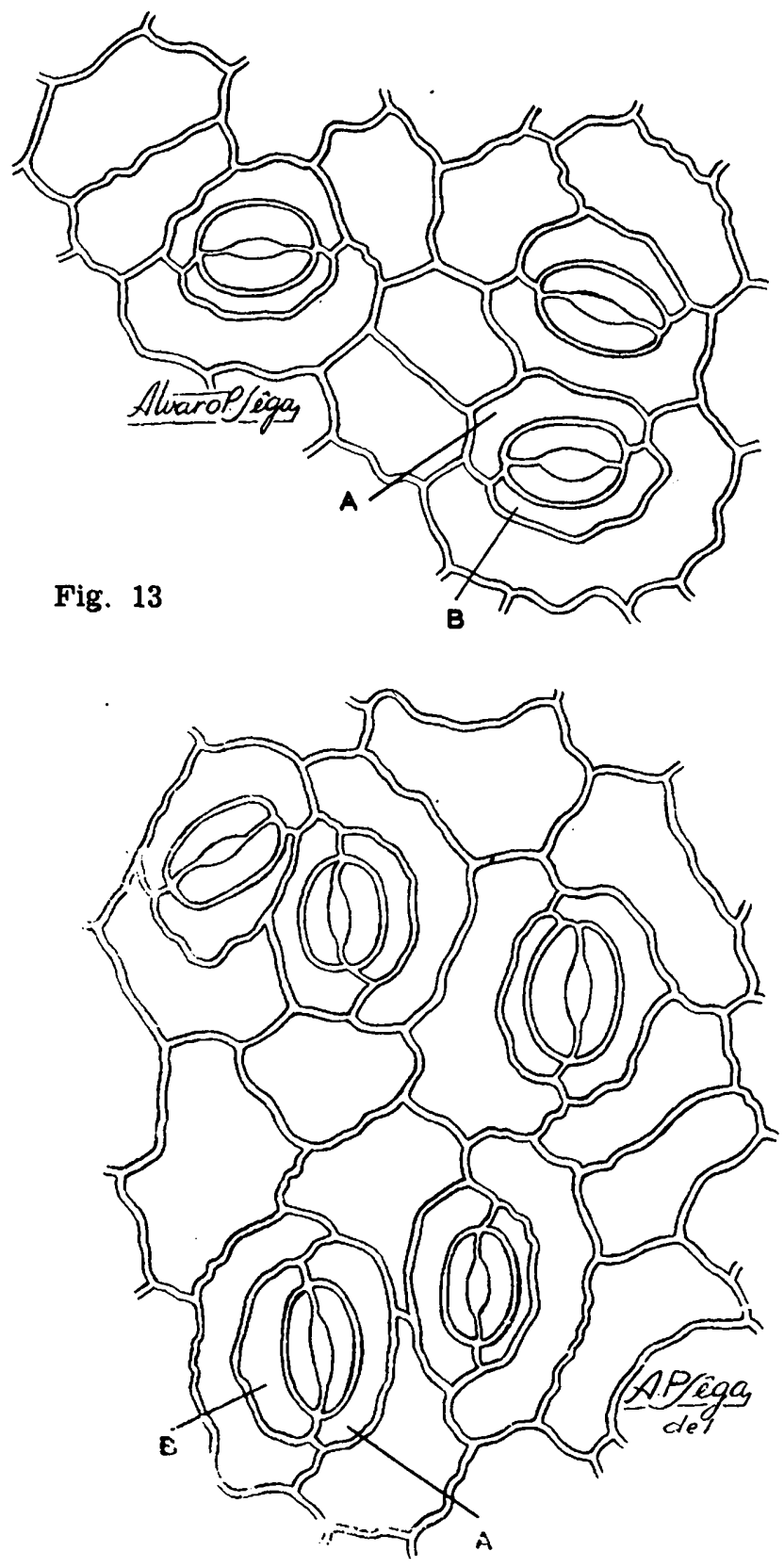

Fig. 14 


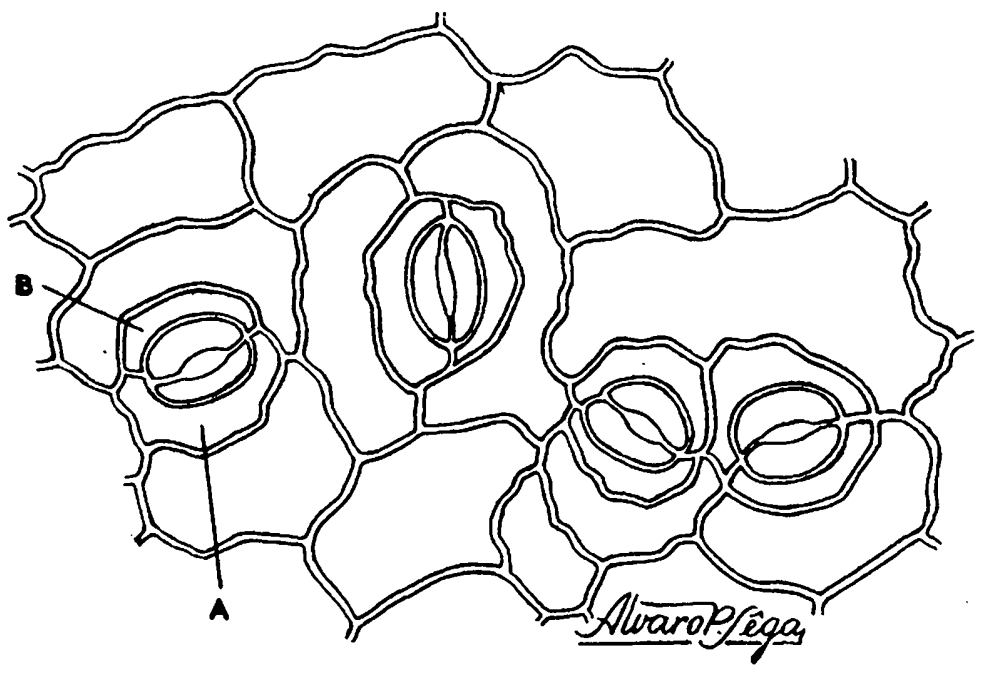

Fig. 15

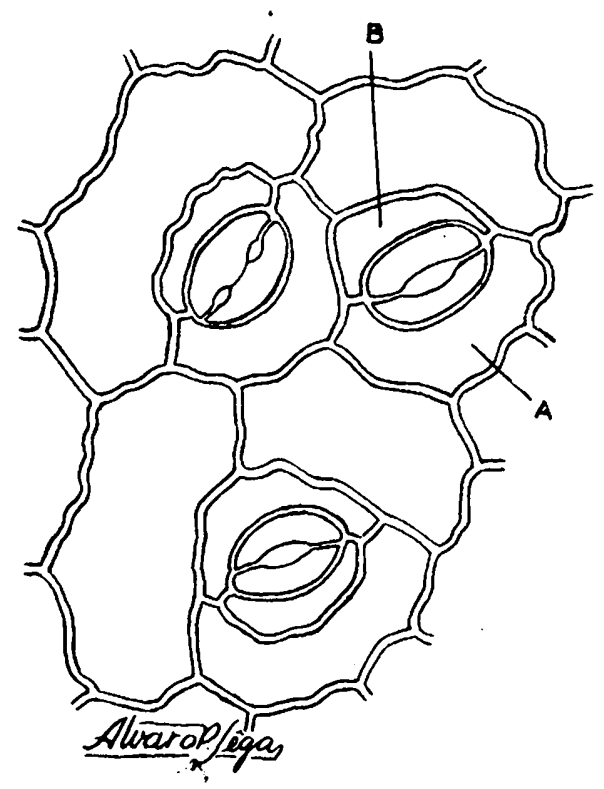

Fig. 16 


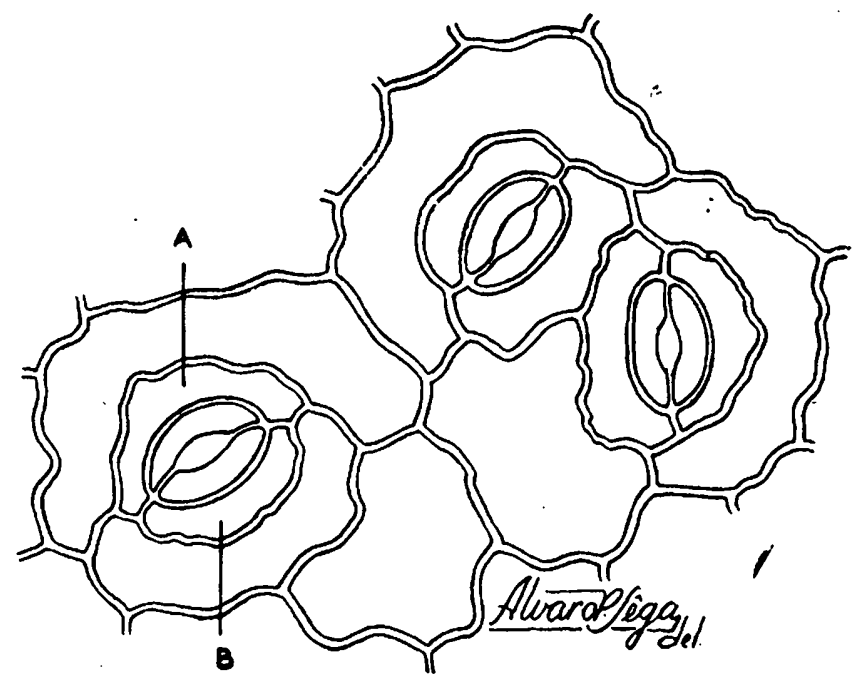

Fig. 17

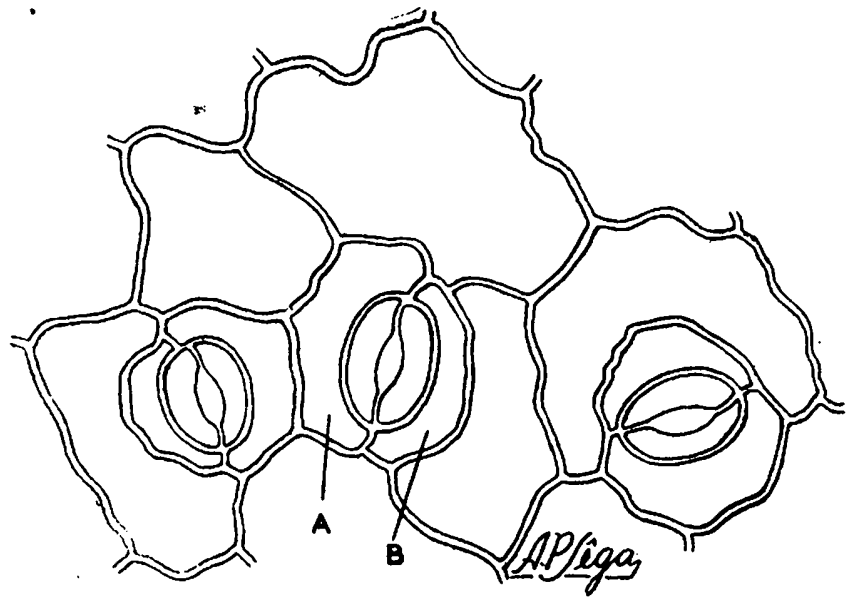

Fig. 18 


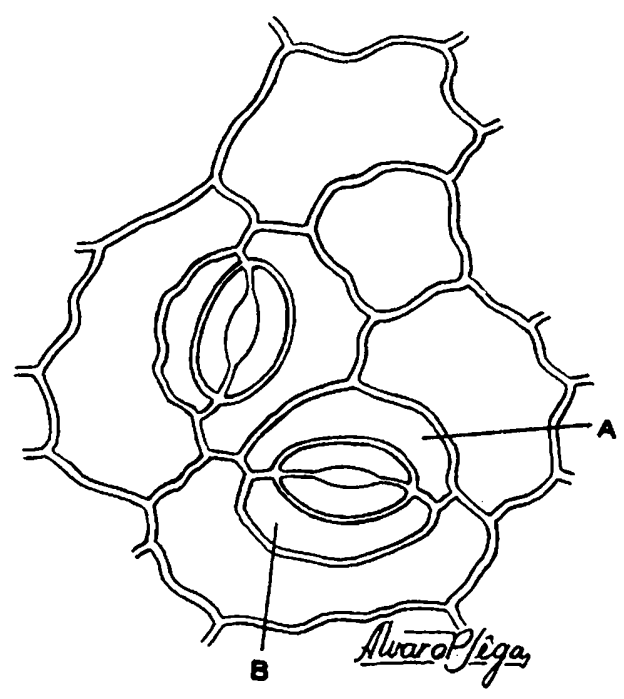

Fig. 19

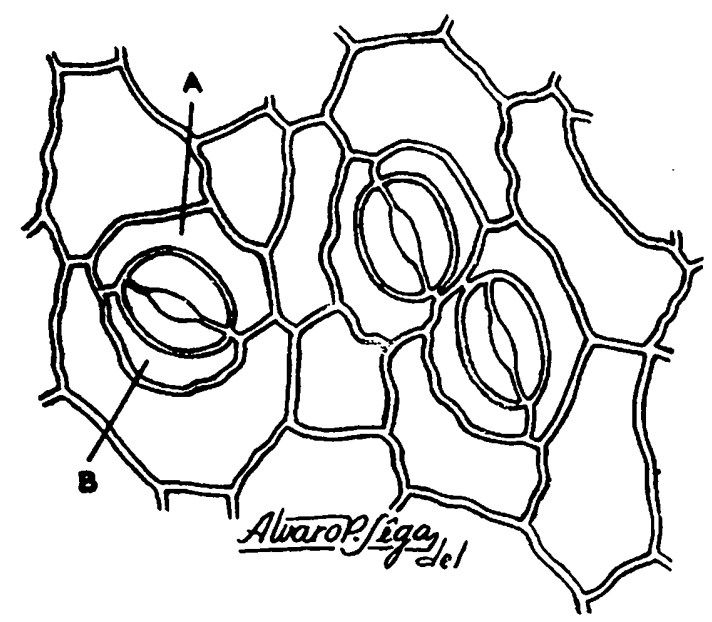

Fig. 20 


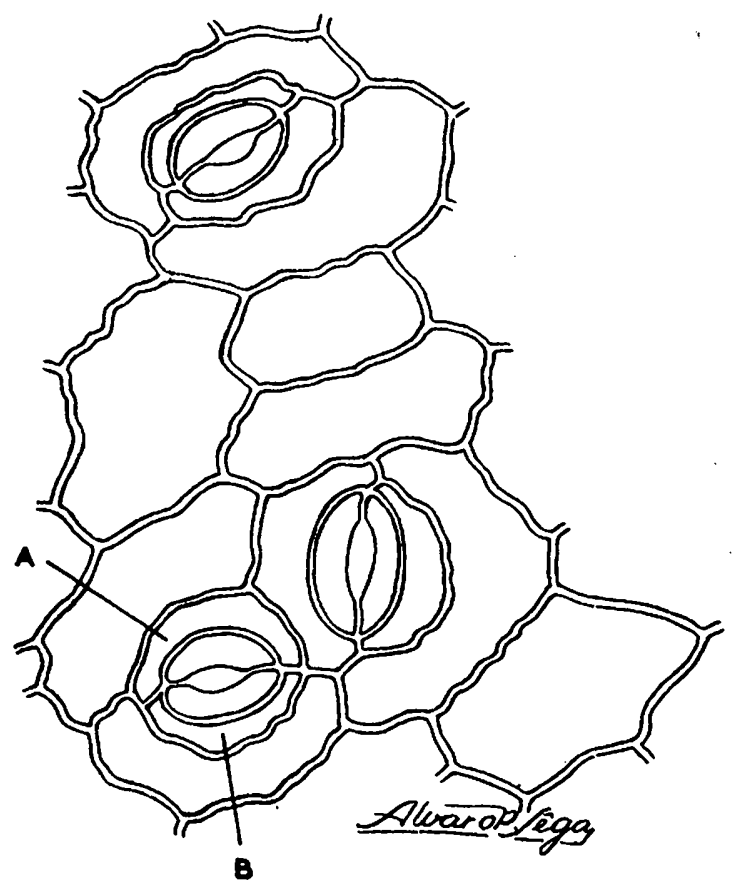

Fig. 21

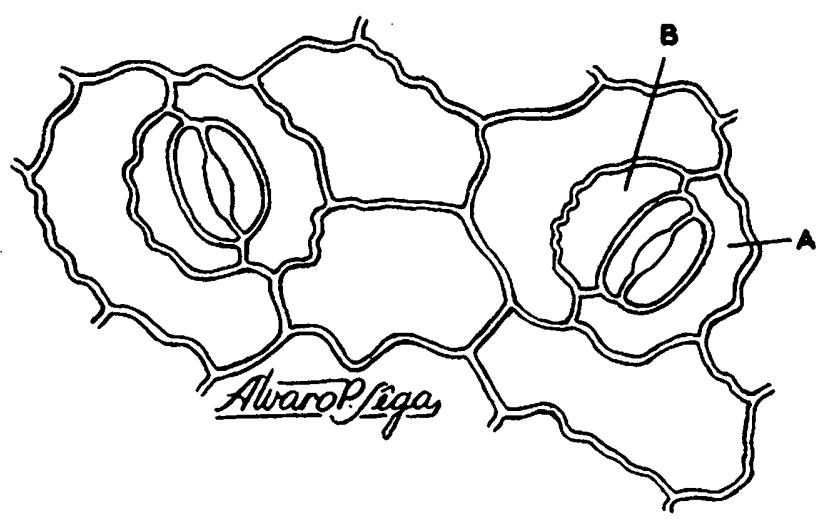

Fig. 22 


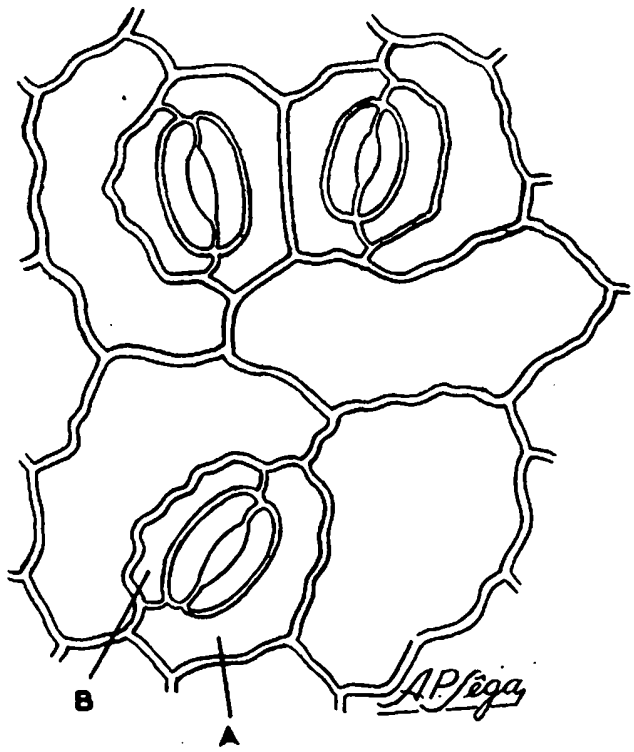

Fig. 23

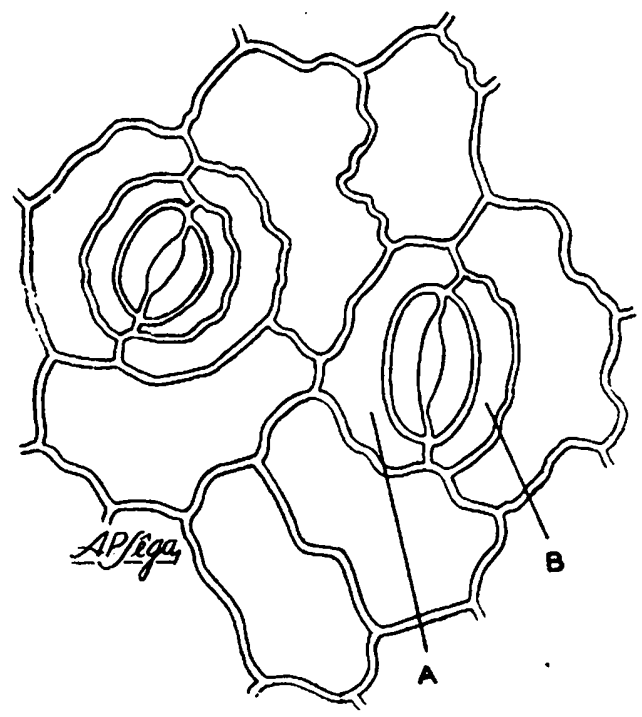

Fig. 24 